\title{
Torsion of a uterine leiomyoma - a rare cause of hemoperitoneum; a case report and review of the literature
}

\author{
Antonia Mihaela Levai, Ioana Cristina Rotar, Daniel Mureșan
}

$1^{\text {st }}$ Obstetrics and Gynecology Department, Emergency County Hospital, “Iuliu Haţieganu” University of Medicine and Pharmacy, Cluj Napoca, Romania

\begin{abstract}
Uterine leiomyomas are common benign uterine tumors but by contrast, their acute complications are very rare. We present an unusual case of 38-year-old woman that came to the emergency department with acute abdominal pain. The ultrasound revealed hemoperitoneum, a uterus with two intramural fibroids and a tender inhomogeneous pelvic mass that seems to connect with the uterus. Computer tomographic (CT) examination raised the suspicion of a degenerated fibroid and hemoperitoneum. Emergency laparotomy was performed: the hemoperitoneum was determined by a degenerated fundal subserosal fibroid. Myomectomy was subsequently carried out. Even though this condition is extremely rare, every clinician has to bear in mind that acute fibroid complications can be a potential cause of acute abdominal pain that requires immediate surgery. The imagistic tools, ultrasound and CT are extremely helpful for the diagnosis.

Due to its relative rarity in the second part of the article we have performed a review of the existing literature regarding the acute complications of fibroid torsion.
\end{abstract}

Keywords: leiomyoma; torsion; hemoperitoneum; fibroid degeneration; acute abdomen

\section{Introduction}

Uterine fibroids, also known as myomas or leiomyomas, represent the commonest tumor in women of reproductive age being encountered in approximately $50-60 \%$ of women [1-3]. The most accurate term is leiomyoma, the tumor being the result of a monoclonal cell proliferation that originates from the uterine smooth muscle tissue and its connective tissue under the influence of ovarian steroids especially progesterone and local factors $[1,2]$. Fibroids can remain asymptomatic during the reproductive life being discovered by routine ultrasound (US) or in about $30-40 \%$ of casesare diagnosed due to their chronic complications [2].

Received 03.11.2018 Accepted 11.12.2018

Med Ultrason

2019, Vol. 21, No 1, 77-82

Corresponding author: Ioana Cristina Rotar

1st Obstetrics and Gynecology Department

3-5 Clinicilor street,

400006 Cluj Napoca, Romania

E-mail: cristina.rotar@umfcluj.ro
Fibroid location represents the key factor for the occurrence of a particular complication. Many fibroid classifications are available; the one from FIGO (International Federation of Gynecology and Obstetrics), based on myoma location correlates best with tumor symptoms and treatment [4]. Intracavitary fibroids can determine heavy menstrual bleeding and therefore iron deficiency anemia, but also infertility, while subserosal fibroids can determine pelvic pressure, chronic pelvic pain, urinary or gastrointestinal symptoms or even hydronephrosis $[2,5]$. The relationship between fibroids and infertility is complex; this type of benign uterine tumors could interfere with fertility through many mechanisms: alteration of endometrial function, increased uterine contractility, impaired endometrial and myometrial blood flow but also alteration of local paracrine factors that can interfere with blastocyst implantation [2].

Extremely rare fibroids can be involved in acute complications such as thromboembolism, acute torsion of subserosal pedunculated leiomyoma, acute urinary retention and renal failure, acute pain caused by red degeneration during pregnancy, acute vaginal or intra-peritoneal 
hemorrhage, mesenteric vein thrombosis and intestinal gangrene [4].

The management of uterine fibroids depends on tumor characteristic: number, size, location of the fibroids but also on patient age and future fertility plans [2]. Surgical therapy is represented by myomectomy or hysterectomy by various approaches: hysteroscopy, laparotomy, laparoscopy or even vaginal surgery. Uterine artery embolization is an alternative to the surgical treatment.

In the following section, we aim to present a rare case of hemoperitoneum due to fibroid degeneration. In the second part of the article we performed a literature analysis regarding imagistic diagnosis and management of fibroids that determined a hemoperitoneum

\section{Case report}

A 38-year-old nulliparous woman, with no gynecologic or medical known conditions, presented at the emergency room for severe abdominal pain progressively aggravated in the last two days, despite self-administration of various antalgic and anti-inflammatory drugs. On the day of admission, besides lower abdominal pain, she also presented nausea, dizziness and intense weakness. The patient reported regular menstrual cycles, her last menstrual period being a week ago. She denied intercourse during the last week. The last gynecological examination had been carried out about two years ago and was within normal limits. On physical examination, the vital signs were within normal limits blood pressure $128 / 84 \mathrm{mmHg}$, heart rate $76 \mathrm{bpm}$ and temperature of $36.5^{\circ} \mathrm{C}$. Abdominal examination showed generalized tenderness and positive Blumberg's sign. Bimanual examination revealed a mobile slightly increased uterus and a tender pelvic mass, about 6 $\mathrm{cm}$ in size thatcould be mobilized together with the uterus.

Hemoglobin concentration was initially $13.6 \mathrm{~g} / \mathrm{dL}$ and two hours later $12.8 \mathrm{~g} / \mathrm{dL}$ with leukocytosis $\left(16.2 \times 10^{9} / \mathrm{L}\right)$. The urine pregnancy test was negative.
US of the pelvis showed uterus into anteversion and anteflexion, with two intramural (FIGO 4) fibroids measuring $1.6 / 1.7 \mathrm{~cm}$ and $2.7 / 3.3 \mathrm{~cm}$ and a pelvic mass besides the uterus measuring 6.9/5.8 $\mathrm{cm}$ (fig 1a,b). Both ovaries were normal. Moderate free pelvic fluid extending into the pouches of Douglas and Morrison was noted. The repeated US examination after 3 hours revealed the above-mentioned pelvic mass of slightly increased dimensions 8.86/6.22 $\mathrm{cm}$ and an increased quantity of free fluid in the peritoneal cavity.

Our initial differential diagnosis was twisted adnexa, ruptured ectopic pregnancy, hemorrhagic corpus luteum or follicular cyst, endometriosis, ruptured ovarian cyst, torsional ovarian fibroma, ruptured pyosalpinx or tuboovarian abscess and even appendicitis.

The computer scan (CT) of the abdomen and pelvis showed a 64/88/68 $\mathrm{mm}$ mass arising from the fundal wall of the uterus with a vascular pedicle suggesting a fibroid (fig 1c,d).

Due to the detection of hemoperitoneum on paracentesis, corroborated with clinical and imagistic examinations, immediate surgery was performed. Intraoperatively, approximately $400 \mathrm{~mL}$ of hemoperitoneum was found originating from the degenerated fundal pediculate fibroid measuring $8 \mathrm{~cm}$, a tumor that has been removed by a myomectomy.

The postoperative recovery was without any incident. Histopathological examination of the mass showed an infarcted and torsion leiomyoma measuring. No increase in mitotic activity has been reported.

The patient was discharged on the fourth day after surgery in the absence of any complication. At 6 weeks postoperative visit the abdominal scar was completely healed, and the ultrasound revealed the presence of the above-mentioned fibroids.

At the scheduled 6-month post-surgery visit, the patient had a viable 6 weeks intrauterine pregnancy.

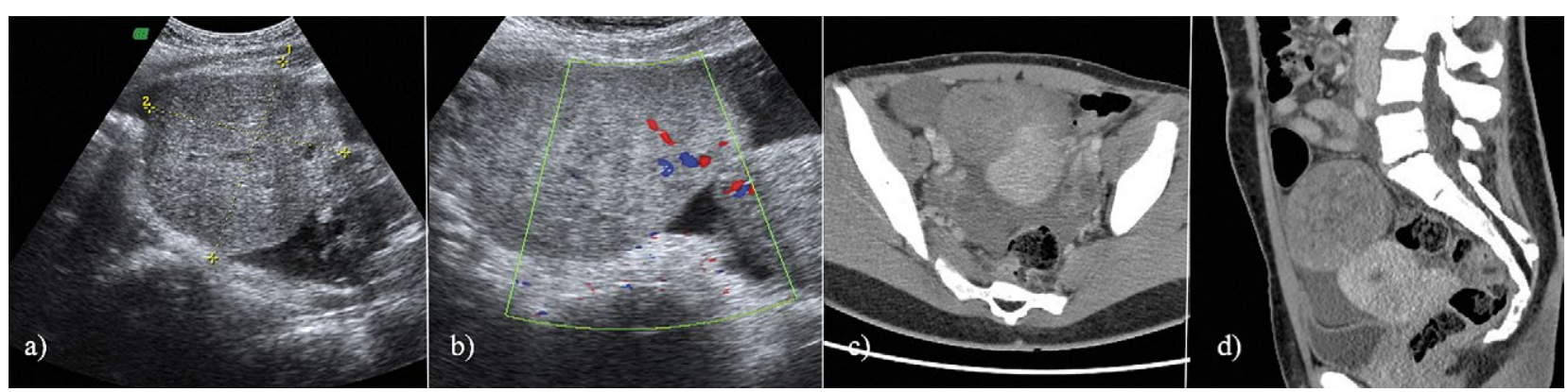

Fig 1. a) Pelvic ultrasound B mode showing a pelvic tumor related to the uterus and free fluid in the abdominal cavity; b) The pelvic mass was highly suggestive for a uterine fibroid; the lump being in close contact with the uterus (CFM mode); c) CT image suggesting a uterine fibroid, transverse section; d) CT image, sagital section 


\section{Discussions}

Spontaneous hemoperitoneum related to fibroids are extremely rare conditions; around 100 cases being reported in the literature [6]. We have performed a search of the literature using the term leiomyoma/fibroids and hemoperitoneum and we found 25 cases reported in the last 10 years (between January 2008 and January 2018) (Table I).

In most of the cases, the condition occurred in women of reproductive age; the mean age of the patients being 35.5 years, ranging from 22 to 62 years. However, Salehi et al [31] reported a case of a 15-year-old adolescent with a 9.5/8.4/10.7 $\mathrm{cm}$ heterogeneous, hypoattenuating, symptomatic solid adnexal mass that resulted in being a degenerative uterine leiomyoma. Several other cases in the puerperal period, in perimenopause or even in postmenopause have been reported $[18,26]$.

The majority of complicated leiomyomas were subserosal (92\%), among them, $44 \%$ being pedunculated. Only one author reported a huge leiomyoma that encompassed the entire uterine corpus. In the latter case, the hemoperitoneum occurred due to the rupture of the dilated superficial vein [24].

The reported leiomyomas complicated with hemoperitoneum varied in size from medium to large dimensions from 4 to $16.3 \mathrm{~cm}$ with a median diameter around $11 \mathrm{~cm}$

The exact etiopathogenetic mechanisms that determine the occurrence of hemoperitoneum in a patient with uterine fibroids are, in some cases, difficult to be identified, the most frequently identified being the rupture of serosal veins or arteries, avulsion, torsion, rupture of a degenerated fibroid.

A precise hemoperitoneum determining cause was reported in several patients: venous congestion, increased abdominal pressure, trauma, rapid growth or degeneration of the fibroid $[3,6]$. Our patient denied trauma, intense physical activity or intercourse during the last week. She also denies any hormonal treatment or use of oral contraceptives. The only mechanism that we can assume is the rapid growth of a fibroid in a young patient, which overcame its possibilities of vascularization and determined degeneration, later torsion and then rupture of the uterine artery.

Horowitz et al [32] described a case of a 48 -year-old woman with a pulsatile bleeding superficial artery, located on the serosal surface of a $14 \mathrm{~cm}$ fundal myoma. In this situation, the authors supposed that intraperitoneal hemorrhage could be caused by the underlying pressure exerted by the growing myoma on the walls of a uterine vessel or by the uterine contractions during menstrua- tion that may distend the blood vessel to the breaking point. Moreover, Lotterman et al [7] described a 28-yearold nulliparous woman that presented hemoperitoneum resulting from surface vein rupture of a large fibroid weighing more than $1300 \mathrm{~g}$. They assumed that the rupture likely occurred after a bowel movement and the increased venous congestion led to vessel rupture in their patient. Schwartz et al [26] concluded that the mechanism responsible for the degeneration and the rupture of a known fibroid in the case of a 53-year-old woman could be related to decreasing levels of estrogen and progesterone in combination with menstrual cycle irregularity.

Rarely, a trauma was depicted in the recent past: Estrade-Huchon et al [11] presented the case of a 46-yearold woman with acute abdominal pain while jogging. Laparoscopy revealed internal bleeding from an avulsed subserosal leiomyoma. In this case abdominal trauma could be responsible for the leiomyoma rupture. By contrast another case of spontaneously avulsion of a uterine leiomyomata in the absence of any trauma was also reported by Pachy et al [10].

Interesting, Swarray-Deen et al [30] described the case of a 43-year-old multiparous woman with massive intra-abdominal hemorrhage due to a $10 \mathrm{~cm}$ subserosal fibroid with a ruptured capsule, 2 days after a spontaneous vaginal delivery. It was a leiomyoma with cystic degeneration. The authors concluded that the degenerative process and the contractions during labor could have precipitated the rupture. Moreover, Tan at al [33] reported a similar case but 9 weeks postpartum. In the latter two cases the hormonal changes during postpartum could have determined the degenerative changes and increased the fragility of the tumor.

Several authors $[14,21,30,34]$ reported acute abdomen syndrome after fibroid degenerescence. Three factors have been identified as potential determining for subserosal myoma torsion: the presence of a long and thin pedicle; the size (larger the fibroids less likely to untwist) and the relationship between the myoma and adjacent viscera (the uterine fundus, intestine and pelvic sidewall) [21]. Twisted fibromas causes venous stasis and later on, edema and congestion that will compromise the arterial blood supply. Later hemorrhagic necrosis and gangrene can appear.

Preoperative diagnosis was difficult due to the rareness of the pathology (in our service it was the first case reported in 30 years) and the absence of any medical history (normal gynecologic examination 2 years prior presentation). Imaging techniques (US, CT) helped us to formulate a preoperative diagnosis that was definitely confirmed by the laparotomy which allowed also the treatment (myomectomy). 
Table I. Analysis of Pubmed available articles on fibroids and hemoperitoneum (accessed on August $1^{\text {st }} 2018$ )

\begin{tabular}{|c|c|c|c|c|c|}
\hline Authors & $\begin{array}{l}\text { Patient } \\
\text { age } \\
\text { (years) }\end{array}$ & $\begin{array}{l}\text { Type of } \\
\text { leiomyoma }\end{array}$ & $\begin{array}{l}\text { Tumor size } \\
(\mathrm{cm} / \mathrm{kg})\end{array}$ & $\begin{array}{l}\text { Cause of } \\
\text { hemorrhage }\end{array}$ & Treatment \\
\hline Lotterman et al (2008) [7] & 28 & $\begin{array}{l}\text { pedunculated, } \\
\text { fundal }\end{array}$ & $\begin{array}{l}16 / 13 / 10 \\
(1.3 \mathrm{~kg})\end{array}$ & surface vein bleeding & myomectomy \\
\hline Ihama et al (2008) [8] & 28 & subserosal, fundal & $10 / 10 / 10$ & $\begin{array}{l}\text { rupture of a subserosal } \\
\text { vein }\end{array}$ & an autopsy case \\
\hline Su et al (2008) [9] & 36 & subserosal, fundal & $15 / 15 / 14$ & dilated vein rupture & myomectomy \\
\hline Pachy et al (2009) [10] & 25 & $\begin{array}{l}\text { pedunculated } \\
\text { anterior }\end{array}$ & $14 / 10 / 6$ & avulsion & myomectomy \\
\hline Estrade-Huchon (2010) [11] & 46 & $\begin{array}{l}\text { pedunculated, } \\
\text { fundal }\end{array}$ & $4 \mathrm{~cm}$ & avulsion & hysterectomy \\
\hline Prior et al (2010) [12] & 35 & $\begin{array}{l}\text { pedunculated, } \\
\text { fundal }\end{array}$ & $\begin{array}{l}23 / 10 / 17 \\
(3.9 \mathrm{~kg})\end{array}$ & rupture of serosal veins & myomectomy \\
\hline Kasum et al (2010) [13] & 37 & $\begin{array}{l}\text { subserosal, fundal, } \\
15 \text { weeks } \\
\text { pregnancy }\end{array}$ & $8.5 / 6.5$ & ruptured vessel & myomectomy \\
\hline Foissac et al (2011) [14] & 62 & $\begin{array}{l}\text { pedunculated, } \\
\text { fundal }\end{array}$ & $16 / 23 / 14$ & torsion & myomectomy \\
\hline Toquero et al (2012) [15] & 43 & subserosal & not mentioned & fibroid laceration & hysterectomy \\
\hline Chen et at (2013) [16] & 22 & subserosal & $13 / 13 / 13$ & $\begin{array}{l}\text { rupture of a superficial } \\
\text { UA }\end{array}$ & $\begin{array}{l}\text { laparoscopic } \\
\text { myomectomy }\end{array}$ \\
\hline $\begin{array}{l}\text { Fontarensky et al (two cases) } \\
(2013)[17]\end{array}$ & 47 & $\begin{array}{l}\text { pedunculated, } \\
\text { fundal }\end{array}$ & $10 / 9 / 7$ & no arterial bleeding & $\begin{array}{l}\text { embolization of } \\
\text { UA, scheduled } \\
\text { hysterectomy }\end{array}$ \\
\hline $\begin{array}{l}\text { Fontarensky et al (two cases) } \\
\text { (2013) [17] }\end{array}$ & 44 & intramural, anterior & $14 / 14 / 8.5$ & no arterial bleeding & $\begin{array}{l}\text { embolization of } \\
\text { UA, scheduled } \\
\text { hysterectomy }\end{array}$ \\
\hline Alharbi et al (2013) [18] & 55 & subserosal fundal & $15 / 12 / 7$ & perforation & hysterectomy \\
\hline Ymeleet al (2013) [19] & 46 & $\begin{array}{l}\text { pedunculated, } \\
\text { fundal }\end{array}$ & $\begin{array}{l}22 / 22 / 22 \\
(5.5 \mathrm{~kg})\end{array}$ & ruptured varices & hysterectomy \\
\hline Hicks et al (2014) [20] & 33 & pedunculated & $7.3 / 6.1 / 6.5$ & avulsion & myomectomy \\
\hline Nigam et al (2014) [21] & 42 & $\begin{array}{l}\text { pedunculated, } \\
\text { fundal }\end{array}$ & $9.2 / 11.7 / 5.2$ & torsion & myomectomy \\
\hline Seet et al (2014) [22] & 55 & subserosal, fundal & $7.3 / 10 / 12$ & $\begin{array}{l}\text { ruptured degenerative } \\
\text { fibroid }\end{array}$ & hysterectomy \\
\hline Peng et al (2015) [23] & 39 & $\begin{array}{l}\text { subserosal, } \\
\text { posterior }\end{array}$ & $8 / 9 / 9$ & spontaneous laceration & hysterectomy \\
\hline Aydin et al (2015) [24] & 31 & $\begin{array}{l}\text { kugel myoma } \\
\text { (large leiomyoma } \\
\text { which encom- } \\
\text { passed the whole } \\
\text { uterine corpus) }\end{array}$ & $\begin{array}{l}\text { like a } 14-16 \\
\text { weeks gesta- } \\
\text { tional uterus }\end{array}$ & $\begin{array}{l}\text { rupture of the dilated } \\
\text { superficial veins }\end{array}$ & $\begin{array}{l}\text { UA ligation } \\
\text { failed, } \\
\text { hysterectomy }\end{array}$ \\
\hline Gulati et al (2016) [25] & 29 & pedunculated & $14 / 19 / 10$ & $\begin{array}{l}\text { ruptured large serosal } \\
\text { vessel }\end{array}$ & myomectomy \\
\hline Schwartz et al (2017) [26] & 53 & subserosal, fundal & $8.8 / 7.3 / 8.3$ & ruptured degenerated & hysterectomy \\
\hline Mizrahi et al (2017) [27] & 39 & $\begin{array}{l}\text { pedunculated, } \\
\text { fundal }\end{array}$ & $10 / 10 / 10$ & $\begin{array}{l}\text { arterial vessel arising } \\
\text { from a right UA }\end{array}$ & $\begin{array}{l}\text { myomectomy } \\
\text { and ligation of a } \\
\text { right UA }\end{array}$ \\
\hline Tajima et al (2015) [28] & 54 & $\begin{array}{l}\text { subserosal, pos- } \\
\text { terior }\end{array}$ & $6.5 / 6 / 5.5$ & $\begin{array}{l}\text { ruptured arterial } \\
\text { aneurysm }\end{array}$ & myomectomy \\
\hline Jenayah et al (2017) [29] & 37 & subserosal, fundal & $10 / 11$ & ruptured dilated vein & myomectomy \\
\hline Swarray-Deen et al (2017) [30] & 43 & subserosal, fundal & $10 / 8$ & ruptured capsule & myomectomy \\
\hline
\end{tabular}

$\mathrm{UA}$ - uterine arteries 
Tsai et al [35] argue that clinical examination together with US is sufficient for a preliminary diagnosis, advocating that no additional advanced radiographic imaging technique is necessary. They justified their option by the fact that emergency surgery must be performed as early as possible to avoid worsening of patient status and avoid consumptive coagulopathy. In our case we considered that the CT scan was helpful and added no significant delay to the patient status, but the use of a CT scan should be considered individualized based also on local resources.

Treatment aims to stop the bleeding and to preserve the uterus, if possible, especially in young women. Myomectomy was reported in $56 \%$ of cases (for details see table I); in the rest of the cases, a hysterectomy was performed [11,15,17-19,22-24]. In only two cases, uterine artery embolization was the first line of treatment for patient hemodynamic stabilization followed by a hysterectomy [17].

The immediate intervention is mandatory; the delayed diagnosis and management being associated with increased morbidity and even mortality - one of the reported cases was an autopsy case of a 28 years old woman [8].

Mizrahi et al [27] described the necessity of the ligation of a right uterine artery because of an arterial vessel arising from a right uterine artery with an active bleeding.

Fontarensky et al [17] described the cases of two nulliparous patients with voluminous uterine fibroids complicated by intraperitoneal hemorrhage. The CT showed no arterial blush suggesting active intraperitoneal extravasation and no adnexal mass bleeding. The authors decided to carry out the embolization of the uterine artery, as an emergency therapeutic management, to ensure hemodynamic stabilization before scheduled surgery. Laparoscopic exploration was performed during the following days, but due to the volume of the fibroids the procedure was converted to laparotomy. Moreover, Takeda et al [36] performed gasless laparo-endoscopic singlesite myomectomy with in-bag manual extraction for a pedunculated subserosal myoma with a torsion measuring $55 / 41 \mathrm{~mm}$, without hemoperitoneum.

\section{Conclusions}

Hemoperitoneum caused by a uterine fibroid is an extremely rare condition; therefore, it has to be considered as a potential diagnosis after ruling out other more frequent causes of intraperitoneal bleeding in reproductive age women. Imagistic techniquesare extremely useful for the diagnosis, US being mandatory. CT can be useful, when available, if the patient is hemodynamically stable. CT can not only evidence the lesion but also the exclusion of other intra-abdominal and extragenital pathologies. Whenever a fibroid is present in a patient with acute abdominal pain, the rupture of the fibroid feeding vessel should be evaluated. Surgery, regardless of the approach, confirms the diagnosis and allows the immediate bleeding arrest and appropriate treatment (myomectomy, hysterectomy).

\section{References}

1. Bulun SE. Uterine fibroids. N Engl J Med 2013;369:13441355.

2. Donnez J, Dolmans MM. Uterine fibroid management: from the present to the future. Hum Reprod Update 2016;22:665686.

3. Baird DD, Dunson DB. Why is parity protective for uterine fibroids? Epidemiology 2003;14:247-250.

4. Munro MG, Critchley HO, Broder MS, Fraser IS; FIGO Working Group on Menstrual Disorders. FIGO classification system (PALM-COEIN) for causes of abnormal uterine bleeding in nongravid women of reproductive age. Int $\mathrm{J}$ Gynaecol Obstet 2011;113:3-13.

5. Mureşan D, Stamatian F, Ona D, et al. Current trends in the treatment of ectopic pregnancy]. Chirurgia (Bucur) 2008;103:73-78.

6. Gupta S, Manyonda IT. Acute complications of fibroids. Best Pract Res Clin Obstet Gynaecol 2009;23:609-617.

7. Lotterman S. Massive hemoperitoneum resulting from spontaneous rupture of uterine leiomyoma. Am J Emerg Med 2008;26:974.e1-e2.

8. Ihama Y, Miyazaki T, Fuke C. Hemoperitoneum due to rupture of a subserosal vein overlying a uterine leiomyoma. Am J Forensic Med Pathol 2008;29:177-180.

9. Su WH, Cheung SM, Chang SP, Lee WL. Internal bleeding from a ruptured serosal vein covering the myoma surface mimicking upper gastrointestinal bleeding. Taiwan J Obstet Gynecol 2008;47:352-354.

10. Pachy F, Lemercier D, Dommergues M, Sibony O. Unusual complication of uterine leiomyoma: spontaneous avulsion with massive hemoperitoneum.J Gynecol Obstet Biol Reprod (Paris) 2009;38:239-241.

11. Estrade-Huchon S, Bouhanna P, Limot O, Fauconnier A, Bader G. Severe life-threatening hemoperitoneum from posttraumatic avulsionof a pedunculated uterine leiomyoma. J Minim Invasive Gynecol 2010;17:651-652.

12. Prior T, Byrne H, Lyons D. Fibroids as a cause of intraperitoneal haemorrhage. J Obstet Gynaecol 2010;30:209.

13. Kasum M. Hemoperitoneum caused by a bleeding myoma in pregnancy. Acta Clin Croat 2010;49:197-200.

14. Foissac R, Sautot-Vial N, Birtwisle L, et al. Torsion of a huge pedunculated uterine leiomyoma. Am J Surg 2011;201:e43-e45.

15. Toquero L, Gadd R, Owers CE, Simms JM. Post-coital haemoperitoneum: a downside to intercourse. Ann R Coll Surg Engl 2012;94:e26-e27. 
16. Chen CH, Lin JY, Tzeng CR, Chiu LH, Liu WM. Hemoperitoneum secondary to rupture of a superficial uterine artery overlying a subserosal myoma with no predisposing factors in a young woman. Taiwan J Obstet Gynecol 2013;52:133134.

17. Fontarensky M, Cassagnes L, Bouchet P, Azuar AS, Boyer L, Chabrot P. Acute complications of benign uterine leiomyomas:treatment of intraperitoneal haemorrhage by embolisation of the uterine arteries. Diagn Interv Imaging 2013;94:885-890.

18. Alharbi SR. Uterine leiomyoma with spontaneous intraleiomyoma hemorrhage, perforation, and hemoperitoneum in postmenopausal woman: Computed tomography diagnosis. Avicenna J Med 2013;3:81-83.

19. Ymele FF, Tsuala JF, Fouedjio JH, et al. A rare complication of uterine leiomyomas: massive hemoperitoneum secondary to ruptured varices. Pan Afr Med J 2013;14: 110.

20. Hicks CW, Garcia L, Howley I, et al. Traumatic hemoperitoneum. JAMA Surg 2014;149:615-616.

21. Nigam A, Raghunandan C, Yadav R. Twisted subserosal leiomyoma in a non-gravid uterus: A rare cause of acute abdomen. J Obstet Gynaecol 2014;34: 657-658.

22. Seet MJ, Chonkar S, Mathur M. An unusual presentation of a ruptured degenerative fibroid in a perimenopausal woman. BMJ Case Rep 2014;2014:2014207473.

23. Peng CR, Chen CP, Wang KG, Wang LK, Chen YY, Chen CY. Spontaneous rupture and massive hemoperitoneum from uterine leiomyomas and adenomyosis in a nongravid and unscarred uterus. Taiwan J Obstet Gynecol 2015;54:198-200.

24. Aydin C, Şen Selim H, Eriş S, Yalçin Y. Haemoperitoneum: an extremely rare complication of leiomyoma. J Obstet Gynaecol 2015;35:109-110.

25. Gulati N, Raman S, Srinivasan M, Bakour S. Rare gynaecological emergency: massive intraperitoneal haemorrhage from spontaneous rupture of a superficial vessel on a large leiomyoma. BMJ Case Rep 2016;2016:bcr2015212576.
26. Schwartz M, Powell K. Spontaneous rupture of a leiomyoma causing life-threatening intra-abdominal hemorrhage. Case Rep Obstet Gynecol 2017;2017:3701450.

27. Mizrahi DJ, Kaushik C, Adamo R. Hypovolemic shock and hemoperitoneum from spontaneous avulsion of a large pedunculated uterine leiomyoma. J Radiol Case Rep 2017;31:15-21.

28. Tajima S, Yonezawa I, Waki M, Hoshi S. Massive hemoperitoneum following spontaneous rupture of an arterial aneurysm overlying a uterine myoma. Int J Clin Exp Med 2015;8:3002-3005.

29. Jenayah AA, Saoudi S, Sferi N, et al. Spontaneous subserosal venous rupture overlying a uterine leiomyoma in a young woman. Pan Afr Med J 2017;28:205.

30. Swarray-Deen A, Mensah-Brown SA, Coleman J. Rare complication of fibroids in pregnancy: spontaneous fibroid rupture. J Obstet Gynaecol Res 2017;43:1485-1488.

31. Salehi PP, Tyson N. Laparoscopic myomectomy of a symptomatic uterine leiomyoma in a 15 -year-old adolescent. J Pediatr Adolesc Gynecol 2016;29:e87-e90.

32. Horowitz E, Dekel A, Feldberg D, Rabinerson D. Massive hemoperitoneum due to rupture of an artery overlying a uterine leiomyoma: a case report. Acta Obstet Gynecol Scand 2005;84:408-409.

33. Tan YL, Naidu A. Rare postpartum ruptured degenerated fibroid: a case report. J Obstet Gynaecol Res 2014;40:14231425.

34. Kosmidis C, Pantos G, Efthimiadis C, Gkoutziomitrou I, Georgakoudi E, Anthimidis G. Laparoscopic excision of a pedunculated uterine leiomyoma in torsion as a cause of acute abdomen at 10 weeks of pregnancy. Am J Case Rep 2015;16:505-508.

35. Tsai YJ, Yeat SK, Jeng CJ, Chen SC. Torsion of a uterine leiomyoma. Taiwanese J Obstet Gynecol 2006;45:333-333.

36. Takeda A, Nakamura H. Torsion of a subserosal myoma managed by gasless laparoendoscopic single-site myomectomy with in-bag manual extraction. Case Rep Obstet Gynecol 2016;2016:7831270. 